Article

\title{
In Vitro Interaction of AB-FUBINACA with Human Cytochrome P450, UDP-Glucuronosyltransferase Enzymes and Drug Transporters
}

\author{
Sunjoo Kim $\left.{ }^{1,+} \mathbb{(}\right)$, Dong Kyun Kim ${ }^{1,+}$, Yongho Shin ${ }^{1}{ }^{\mathbb{D}}$, Ji-Hyeon Jeon ${ }^{2}$, Im-Sook Song ${ }^{2, * \mathbb{C}}$ \\ and Hye Suk Lee ${ }^{1, *(\mathbb{D})}$ \\ 1 Drug Metabolism and Bioanalysis Laboratory, College of Pharmacy, The Catholic University of Korea, \\ Bucheon 14662, Korea; sjkim712@catholic.ac.kr (S.K.); kdk3124@catholic.ac.kr (D.K.K.); \\ driger6103@catholic.ac.kr (Y.S.) \\ 2 College of Pharmacy and Research Institute of Pharmaceutical Sciences, Kyungpook National University, \\ Daegu 41566, Korea; kei7016@naver.com \\ * Correspondence: isssong@knu.ac.kr (I.-S.S.); sianalee@catholic.ac.kr (H.S.L.) \\ + These authors contributed equally to this work.
}

Received: 7 September 2020; Accepted: 5 October 2020; Published: 8 October 2020

\begin{abstract}
AB-FUBINACA, a synthetic indazole carboxamide cannabinoid, has been used worldwide as a new psychoactive substance. Because drug abusers take various drugs concomitantly, it is necessary to explore potential AB-FUBINACA-induced drug-drug interactions caused by modulation of drug-metabolizing enzymes and transporters. In this study, the inhibitory effects of AB-FUBINACA on eight major human cytochrome P450s (CYPs) and six uridine 5 '-diphospho-glucuronosyltransferases (UGTs) of human liver microsomes, and on eight clinically important transport activities including organic cation transporters (OCT) 1 and OCT2, organic anion transporters (OAT) 1 and OAT3, organic anion transporting polypeptide transporters (OATP)1B1 and OATP1B3, P-glycoprotein, and breast cancer resistance protein (BCRP) in transporter-overexpressing cells were investigated. AB-FUBINACA inhibited CYP2B6-mediated bupropion hydroxylation via mixed inhibition with $K_{i}$ value of $15.0 \mu \mathrm{M}$ and competitively inhibited CYP2C8-catalyzed amodiaquine $\mathrm{N}$-de-ethylation, CYP2C9-catalyzed diclofenac 4'-hydroxylation, CYP2C19-catalyzed [S]-mephenytoin $4^{\prime}$-hydroxylation, and CYP2D6-catalyzed bufuralol $1^{\prime}$-hydroxylation with $K_{i}$ values of 19.9, 13.1, 6.3, and $20.8 \mu \mathrm{M}$, respectively. AB-FUBINACA inhibited OCT2-mediated $\mathrm{MPP}^{+}$uptake via mixed inhibition $\left(K_{i}, 54.2 \mu \mathrm{M}\right)$ and competitively inhibited OATP1B1-mediated estrone-3-sulfate uptake $\left(K_{i}, 94.4 \mu \mathrm{M}\right)$. However, AB-FUBINACA did not significantly inhibit CYP1A2, CYP2A6, CYP3A4, UGT1A1, UGT1A3, UGT1A4, UGT1A6, or UGT2B7 enzyme activities at concentrations up to $100 \mu \mathrm{M}$. AB-FUBINACA did not significantly inhibit the transport activities of OCT1, OAT1/3, OATP1B3, P-glycoprotein, or BCRP at concentrations up to $250 \mu \mathrm{M}$. As the pharmacokinetics of AB-FUBINACA in humans and animals remain unknown, it is necessary to clinically evaluate potential in vivo pharmacokinetic drug-drug interactions induced by AB-FUBINACA-mediated inhibition of CYP2B6, CYP2C8, CYP2C9, CYP2C19, CYP2D6, OCT2, and OATP1B1 activities.
\end{abstract}

Keywords: AB-FUBINACA; drug-drug interaction; cytochrome P450; uridine 5'-diphosphoglucuronosyltransferases; drug transporters

\section{Introduction}

Synthetic cannabinoids (SCs) are new psychoactive substances mimicking $\Delta 9$-tetrahydrocannabinol (THC), the active component of cannabis, and typically bind to the cannabinoid receptor type 1 (CB1) or type 2 (CB2) [1]. SC misuse has increased worldwide; 169 SCs are monitored by the European 
Monitoring Centre for Drugs and Drug Addiction (EMCDDA) via the EU Early Warning System established in December 2016.

AB-FUBINACA ( $N$-[(1S)-1-(aminocarbonyl)-2-methylpropyl]-1-[(4-fluorophenyl)methyl]-1Hindazole-3-carboxamide) is an SC (an indazole carboxamide) (Figure 1) exhibiting CB1 and CB2 agonist activities with $\mathrm{EC}_{50}$ values of 1.8 and $3.2 \mathrm{nM}$, respectively [2]. AB-FUBINACA was developed by Pfizer in 2009 as an analgesic drug candidate, but development was not pursued. The material was identified for the first time in Japanese herbal smoking blends in 2012 and has been included in Schedule I of the Controlled Substances Act by the US Drug Enforcement Administration since 2014 [3,4]. Use is controlled nationally in Germany, China, and Canada; and by the United Nations Office on Drugs and Crime.

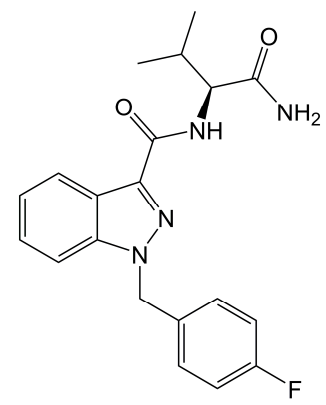

Figure 1. Chemical structure of AB-FUBINACA.

AB-FUBINCA induced acute neurological disorders such as hyperreflexia, sensorimotor alterations, and spontaneous aggressiveness in mice when administered intraperitoneally at a single dose of $6 \mathrm{mg} / \mathrm{kg}$ [5]. In humans, the symptoms reported after intoxication of SCs are tachycardia, agitation, drowsiness, and vomiting etc. [4]. Repeated exposure of SCs leads to cause serious adverse reaction including coma and death. Among the cases of severe toxic effects and deaths associated with SCs reported from 2012 to 2015, the most prevalent cases were AB-CHIMICA and cases related to AB-FUBINACA, ADB-FUBINACA, AM2201, and JWH-018 were also reported [6,7]. In addition, metabolites of SCs such as JWH-018 and JWH-073 often retain higher affinity to CB1 or CB2 than THC [8]. Given the toxic events and increasing use of SCs and retained activity of SC metabolites, determination of SCs and their metabolites in serum, urine, hepatocytes, and liver microsomes has been developed [7]. AB-FUBINACA is extensively metabolized via hydrolysis of the amide group carboxylesterases 1 (CES1) and CES2, hydroxylation of the amino-oxobutane moiety and imidazole ring, defluorobenzylation and dehydrogenation by cytochrome P450s (CYPs) 2C19, 3A4, and 3A5, glucuronidation, and combinations thereof ([9-12], our unpublished data). The major metabolites of AB-FUBINACA identified after human liver microsomal incubation are different significantly from those in authentic human urine samples [9]. Hydrolysis of the amide group by carboxylesterases 1 (CES1) and CES2 and hydroxylation of the amino-oxobutane moiety are major metabolites found in urine and microsome samples $[9,10]$ but hydroxylation of an imidazole ring and its glucuronide metabolite were mainly identified in intoxicated human urine samples [9].

Drug abusers frequently take several drugs concomitantly [13-15]; it is thus necessary to investigate the inhibitory effects of drugs on major drug-metabolizing enzymes such as cytochrome P450s (CYPs) and 5'-diphospho-glucuronosyltransferases (UGTs); and on clinically important drug transporters such as solute carrier transporters including the organic cation transporters (OCT)1, and OCT2, the organic anion transporters (OAT) 1 and OAT3, the organic anion transporting polypeptides (OATP)1B1 and OATP1B3, and efflux transporters such as P-glycoprotein (P-gp) and breast cancer-resistance protein (BCRP) [16-18]. The inhibitory effects of phytocannabinoids including THC, cannabinol, cannabidiol [19-25], and synthetic cannabinoids (JWH-019, STS-135, UR-144, AM-2201, MAM-2201, EAM-2201, and APINACA) [4,26-30], on the major CYP and UGT enzymes or human liver microsomes, or recombinant CYP and UGT enzymes, have been reported [19-30]. 
Various drugs of abuse engage in transporter-mediated drug-drug interactions (DDIs); buprenorphine, norbuprenorphine, ibogaine, methadone, and THC-inhibited P-gp of HEK293-MDR1 cells; buprenorphine, norbuprenorphine, and ibogaine inhibited BCRP of HEK293-BCRP cells [31]; THC, cannabinol, cannabidiol, JWH-200, and WIN-55,212-2 inhibited BCRP ATPase activity [32,33]; and elaucine, JWH-200, mitragynine, and WIN-55,212-2 inhibited P-gp of Caco-2 cells [34]. The in vitro and in vivo inhibitory effects of AB-FUBINACA on major human drug-metabolizing enzymes, such as CYPs and UGTs, solute carrier transporters, and efflux transporters, remain unknown. We investigated the in vitro inhibitory effects of AB-FUBINACA on the activities of eight major CYPs and six UGTs of pooled human liver microsomes and on the transport activities of six solute carrier transporters and two efflux transporters of transporter-overexpressing cells, to predict potential AB-FUBINACA-induced DDIs.

\section{Results}

\subsection{Inhibitory Effects of AB-FUBINACA on CYP and UGT Enzyme Activities of Human Liver Microsomes}

The reversible and time-dependent inhibitory effects $\left(\mathrm{IC}_{50}\right.$ values $)$ of $\mathrm{AB}$-FUBINACA on eight major human CYP enzyme activities of ultrapooled human liver microsomes were evaluated using a cocktail of CYP substrates and liquid chromatography-tandem mass spectrometry (LC-MS/MS) (Figure 2 and Table 1). AB-FUBINACA inhibited CYP2B6-mediated bupropion hydroxylation, CYP2C8-mediated amodiaquine $\mathrm{N}$-de-ethylation, CYP2C9-mediated diclofenac 4'-hydroxylation, CYP2C19-mediated [S]-mephenytoin 4'-hydroxylation, and CYP2D6-mediated bufuralol 1'-hydroxylation by ultrapooled human liver microsomes with $\mathrm{IC}_{50}$ values of $29.9,44.3,13.5,19.7$, and $40.4 \mu \mathrm{M}$, respectively (Figure 2 and Table 1). A 30-min preincubation of AB-FUBINACA with ultrapooled human liver microsomes and reduced $\beta$-nicotinamide adenine dinucleotide phosphate (NADPH) did not decrease the $\mathrm{IC}_{50}$ values of AB-FUBINACA for CYP2B6, CYP2C8, CYP2C9, CYP2C19, or CYP2D6 with a slight increase in CYP2B6, CYP2C8, and CYP2D6. It indicates that AB-FUBINACA inhibits the activities of CYP2B6, CYP2C8, CYP2C9, CYP2C19, or CYP2D6 in a concentration-dependent manner but it does not show time-dependent inhibition (Figure 2 and Table 1). AB-FUBINACA did not significantly inhibit CYP1A2-mediated phenacetin O-de-ethylation, CYP2A6-mediated coumarin 7-hydroxylation, or CYP3A4-mediated midazolam 1'-hydroxylation $\left(\mathrm{IC}_{50}>100 \mu \mathrm{M}\right)$ by ultrapooled human liver microsomes with or without 30 min preincubation (Figure 2 and Table 1).

Table 1. Inhibitory potential of AB-FUBINACA on eight major cytochrome P450 (CYP) enzyme activities of ultrapooled human liver microsomes in the presence and absence of 30-min preincubation with NADPH.

\begin{tabular}{cccc}
\hline & & \multicolumn{2}{c}{ IC $_{\mathbf{5 0}}(\boldsymbol{\mu M})$} \\
\cline { 3 - 4 } CYPs & Enzyme Activity & No Preincubation & $\begin{array}{c}\text { With 30 } \\
\text { min-Preincubation }\end{array}$ \\
\hline 1A2 & Phenacetin O-de-ethylase & $>100$ & $>100$ \\
2A6 & Coumarin 7-hydroxylase & $>100$ & $>100$ \\
2B6 & Bupropion hydroxylase & 29.9 & 63.8 \\
2C8 & Amodiaquine N-de-ethylase & 44.3 & 56.2 \\
2C9 & Diclofenac 4'-hydroxylase & 13.5 & 14.8 \\
2C19 & {$[$ S]-Mephenytoin 4'-hydroxylase } & 19.7 & 18.5 \\
2D6 & Bufuralol 1'-hydroxylase & 40.4 & 96.8 \\
3A4 & Midazolam 1'-hydroxylase & $>100$ & $>100$ \\
\hline
\end{tabular}

The data represent the average of three measurements.

The enzyme kinetic study revealed that AB-FUBINACA competitively inhibited amodiaquine $N$-de-ethylase, diclofenac $4^{\prime}$-hydroxylase, [S]-mephenytoin $4^{\prime}$-hydroxylase, and bufuralol $1^{\prime}$-hydroxylase activities with $K_{i}$ values of $19.9,13.1,6.3$, and $20.8 \mu \mathrm{M}$, respectively, but exhibited mixed 
inhibition of bupropion hydroxylase of ultrapooled human liver microsomes with $K_{i}$ value of $15.0 \mu \mathrm{M}$ (Figure 3 and Table 2).
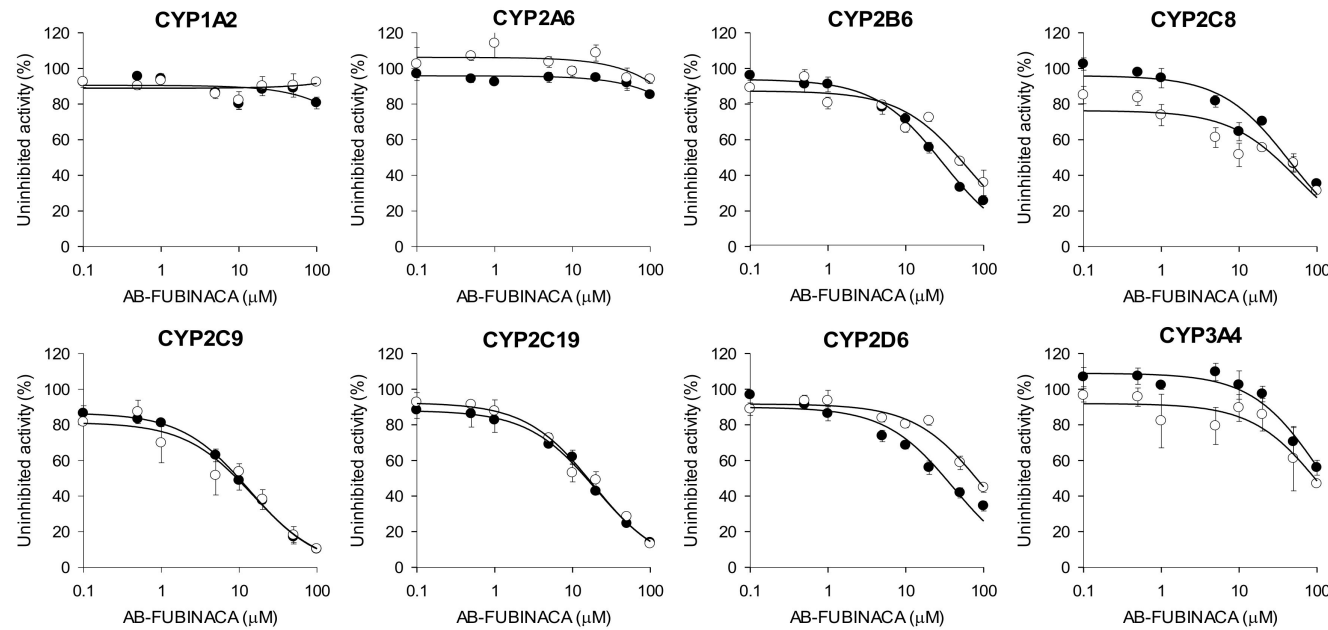

Figure 2. Inhibitory effects of AB-FUBINACA on CYP1A2-mediated phenacetin O-de-ethylation, CYP2A6-mediated coumarin 7-hydroxylation, CYP2B6-mediated bupropion hydroxylation, CYP2C8- mediated amodiaquine $N$-de-ethylation, CYP2C9-mediated diclofenac $4^{\prime}$-hydroxylation, CYP2C19-mediated [S]-mephenytoin 4'-hydroxylation, CYP2D6-mediated bufuralol 1'-hydroxylation, and CYP3A4-mediated midazolam $1^{\prime}$-hydroxylation by ultrapooled human liver microsomes with $(\bigcirc)$ and without $\left(-30\right.$-min preincubation with NADPH at $37^{\circ} \mathrm{C}$. The concentrations of cocktail CYP substrates were $50 \mu \mathrm{M}$ phenacetin, $2.5 \mu \mathrm{M}$ coumarin, $2.0 \mu \mathrm{M}$ amodiaquine, $10 \mu \mathrm{M}$ diclofenac, $100 \mu \mathrm{M}$ [S]-mephenytoin, $5.0 \mu \mathrm{M}$ bufuralol, $2.5 \mu \mathrm{M}$ midazolam, and $50 \mu \mathrm{M}$ bupropion. The data are means \pm SDs $(n=3)$.
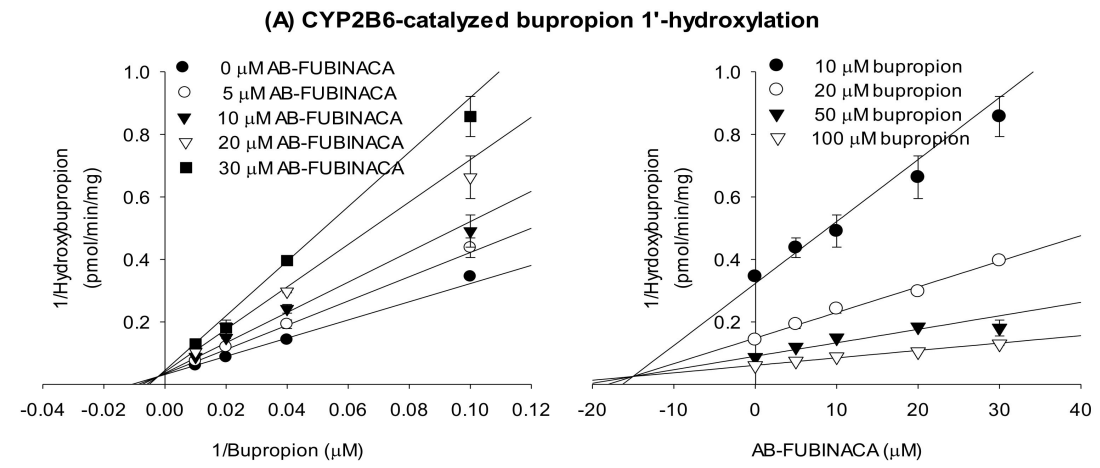

(B) CYP2C8-catalyzed amodiaquine $\mathbf{N}$-deethylation
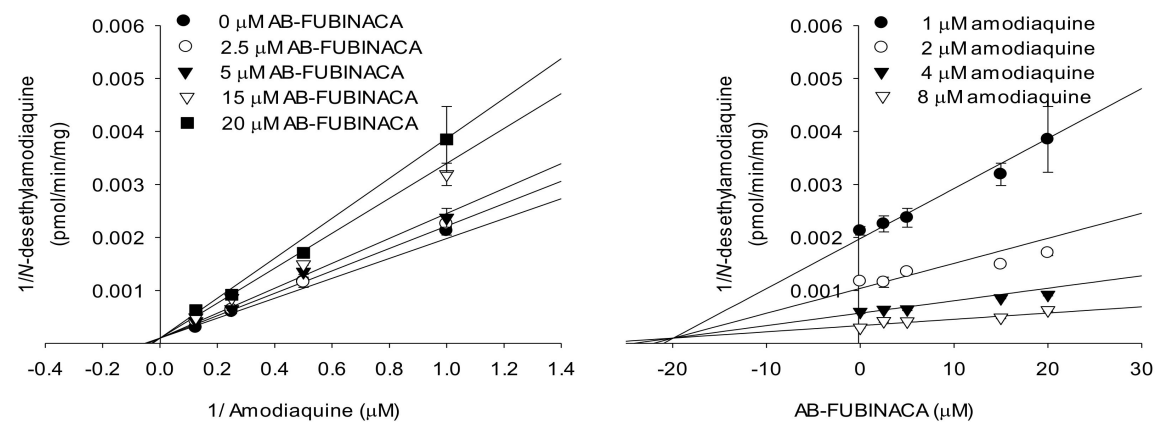

Figure 3. Cont. 
(C) CYP2C9-catalyzed diclofenac 4'-hydroxylation
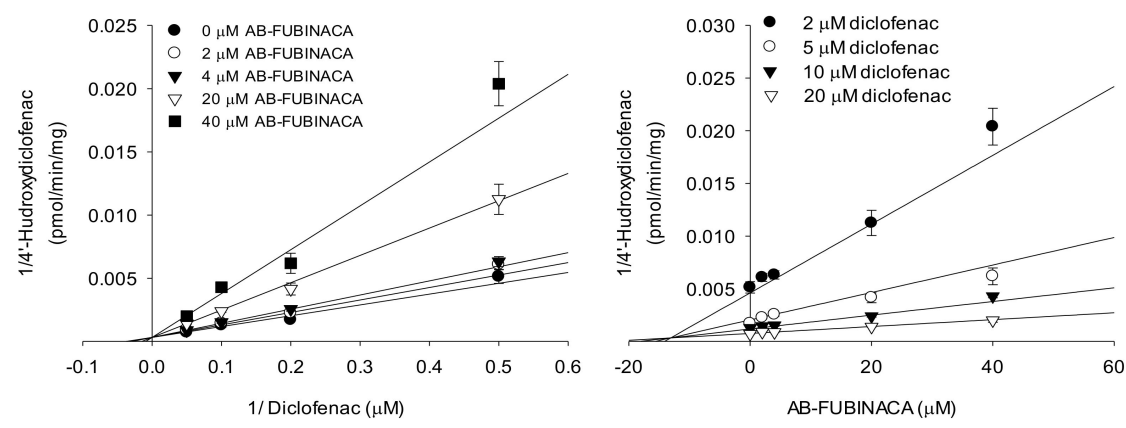

(D) CYP2C19-catalyzed [S]-mephenytoin 4'-hydroxylation
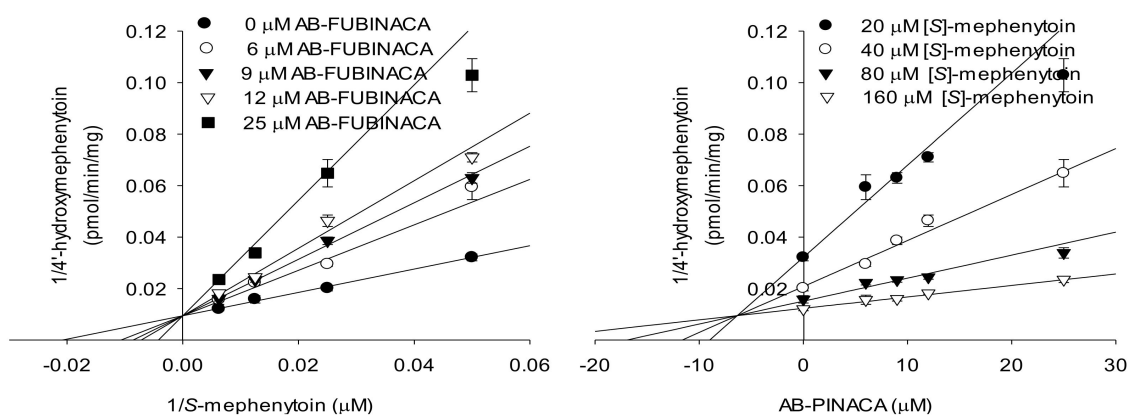

(E) CYP2D6-catalyzed bufuralol 1'-hydroxylation
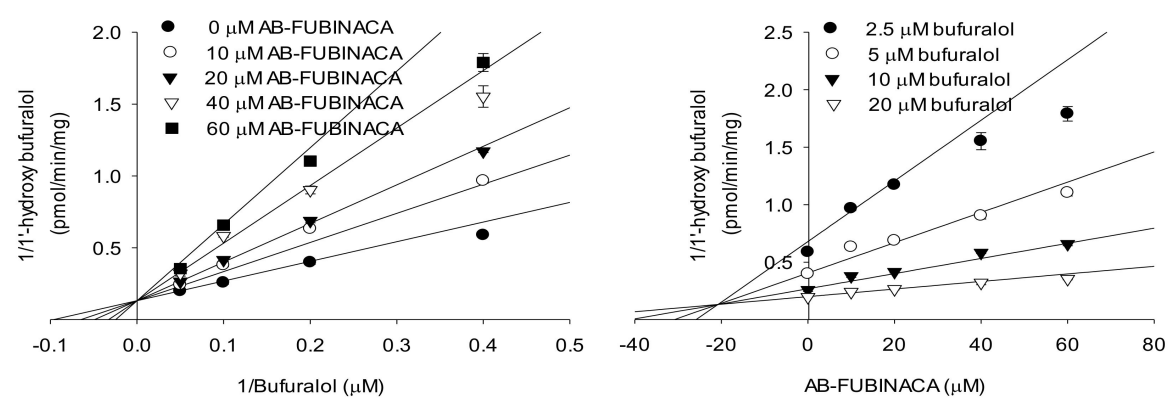

Figure 3. Lineweaver-Burk (left panel) and Dixon (right panel) plots of the inhibitory effects of AB-FUBINACA on (A) bupropion 1'-hydroxylase (CYP2B6), (B) amodiaquine $N$-de-ethylase (CYP2C8), (C) diclofenac 4'-hydroxylase (CYP2C9), (D) [S]-mephenytoin 4'-hydroxylase (CYP2C19), and (E) bufuralol 1'-hydroxylase (CYP2D6) of ultrapooled human liver microsomes. The data are means \pm SDs $(n=3)$.

Table 2. Enzyme kinetic parameters revealing the inhibitory potential of AB-FUBINACA in terms of the CYP and drug transporter activities of pooled human liver microsomes.

\begin{tabular}{cccc}
\hline CYPs & Enzyme Activity & $\boldsymbol{K}_{\mathbf{i}}(\boldsymbol{\mu M})$ & Inhibition Mode \\
\hline 2B6 & Bupropion hydroxylase & 15.0 & Mixed \\
2C8 & $\begin{array}{c}\text { Amodiaquine } \\
\text { N-de-ethylase }\end{array}$ & 19.9 & Competitive \\
2C9 & $\begin{array}{c}\text { Diclofenac } \\
4^{\prime} \text {-hydroxylase }\end{array}$ & 13.1 & Competitive \\
& $\begin{array}{c}\text { S]-Mephenytoin } \\
4^{\prime} \text {-hydroxylase }\end{array}$ & 6.3 & Competitive \\
2C19 & Bufuralol 1'-hydroxylase & 20.8 & Competitive \\
\hline
\end{tabular}

AB-FUBINACA at $100 \mu \mathrm{M}$ negligibly inhibited UGT1A1-catalyzed SN-38 glucuronidation, UGT1A3-catalyzed chenodeoxycholic acid 24-acyl- $\beta$-glucuronidation, UGT1A4-catalyzed trifluoperazine 
$N$-glucuronidation, UGT1A6-catalyzed N-acetylserotonin glucuronidation, UGT1A9-catalyzed mycophenolic acid glucuronidation, and UGT2B7-catalyzed naloxone 3- $\beta$-D-glucuronidation by human liver microsomes (Figure 4).
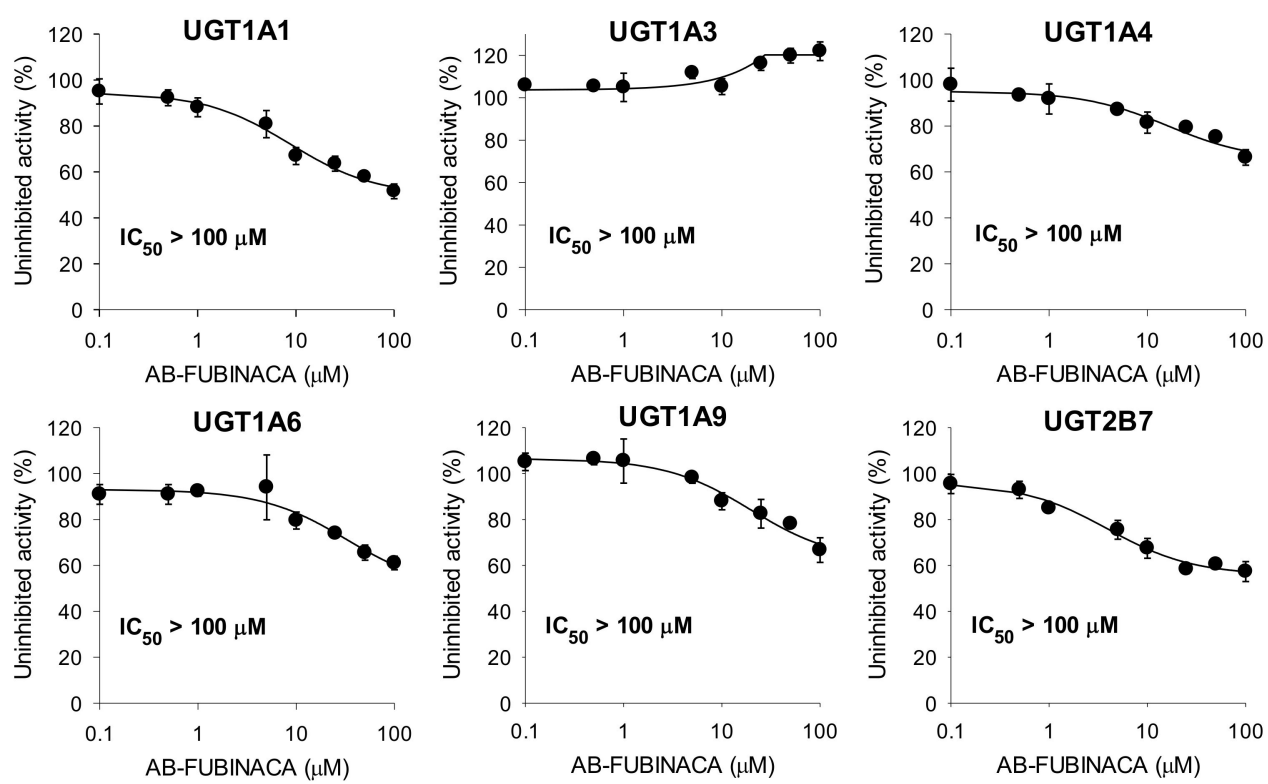

Figure 4. Inhibitory effects of AB-FUBINACA on uridine 5'-diphospho-glucuronosyltransferase (UGT)1A1-catalyzed SN-38 glucuronidation, UGT1A3-catalyzed chenodeoxycholic acid 24-acyl$\beta$-glucuronidation, UGT1A4-catalyzed trifluoperazine $N$-glucuronidation, UGT1A6-catalyzed $N$-acetylserotonin glucuronidation, UGT1A9-catalyzed mycophenolic acid glucuronidation, and UGT2B7-catalyzed naloxone 3- $\beta$-D-glucuronidation by ultrapooled human liver microsomes. The concentrations of cocktail UGT substrates were $0.5 \mu \mathrm{M}$ SN-38, $2 \mu \mathrm{M}$ chenodeoxycholic acid, $0.5 \mu \mathrm{M}$ trifluoperazine, $1 \mu \mathrm{M} N$-acetylserotonin, $0.2 \mu \mathrm{M}$ mycophenolic acid, and $1 \mu \mathrm{M}$ naloxone. The data are means $\pm \operatorname{SDs}(n=3)$.

\subsection{Inhibitory Effects of AB-FUBINACA on Drug Transporters}

The inhibitory effects of AB-FUBINACA on eight major transporters were evaluated using mammalian cells overexpressing OCT1, OCT2, OAT1, OAT3, OATP1B1, OATP1B3, P-gp, and BCRP. As shown in Figure 5, AB-FUBINACA inhibited OCT2-mediated MPP ${ }^{+}$uptake and OATP1B1-mediated estrone-3-sulfate (ES) uptake in a concentration-dependent manner; the inhibition curves yielded $\mathrm{IC}_{50}$ values of $51.3 \mu \mathrm{M}$ and $85.6 \mu \mathrm{M}$, respectively. AB-FUBINACA did not significantly inhibit the transport activities of OCT1, OAT1, OAT3, and OATP1B3 over the concentration ranges tested (Figure 5).

The $\mathrm{B}$ to A transport rate of digoxin and ES, which was calculated as the slope of the graph, in LLC-PK1-MDR1 and LLC-PK1-BCRP cells was 6.5-fold and 5.4-fold, respectively, greater than that in LLC-PK1-mock cells. Net efflux ratios of digoxin and ES were 6.6 and 6.2, respectively, in LLC-PK1-MDR1 and -BCRP cells compared with LLC-PK1-mock cells (Figure 6A,D). The results suggest the feasibility of P-gp- and BCRP-mediated transport system. The effect of AB-FUBINACA on the P-gp- and BCRP-mediated B to A transport of digoxin and ES, respectively, was measured in a concentration range of $0.1-100 \mu \mathrm{M}$ of AB-FUBINACA (Figure 6B,E) to calculate the $\mathrm{IC}_{50}$ value of AB-FUBINACA for P-gp and BCRP. As results, AB-FUBINACA did not inhibit the P-gp-mediated B to A transport rate of digoxin (Figure 6C) and the BCRP-mediated B to A transport rate of ES (Figure 6F) over the concentration ranges tested. 

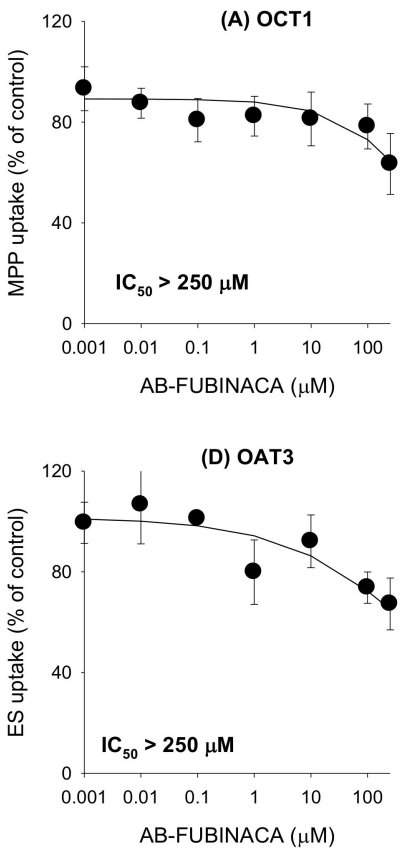

(B) OCT2

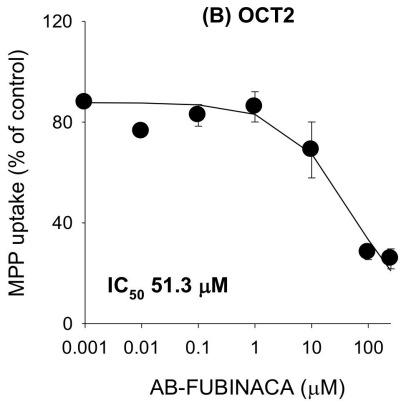

(E) OATP1B1

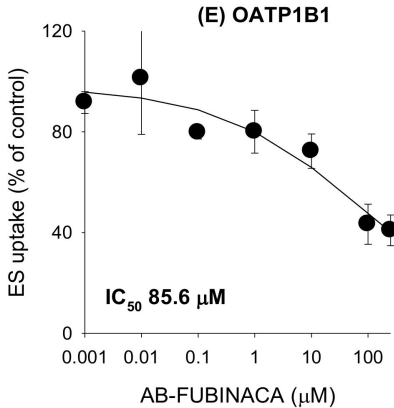

(C) OAT1
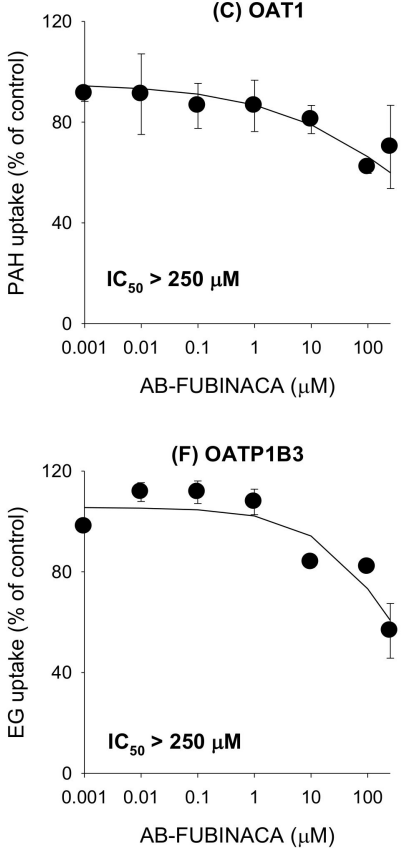

Figure 5. The inhibitory effects of AB-FUBINACA $(0.001-250 \mu \mathrm{M})$ on the uptake of the probe substrate by (A) organic cation transporter (OCT)1, (B) OCT2, (C) organic anion transporter (OAT)1, (D) OAT3, (E) OATP1B1, and (F) OATP1B3 transporters. The concentrations and probe substrates were as follows: $0.1 \mu \mathrm{M}$ [3-H]methyl-4-phenylpyridinium (for OCT1 and OCT2), $0.1 \mu \mathrm{M}$ [3-H]para-aminohippuric acid (for OAT1), $0.1 \mu \mathrm{M}$ [3-H] estrone-3-sulfate (ES) (for OAT3 and OATP1B1), $0.1 \mu \mathrm{M}$ [3-H] estradiol-17 $\beta$-D-glucuronide (for OATP1B3). Transporter-mediated uptake of probe substrate was calculated by subtracting the uptake of probe substrate in HEK293-mock cells from the uptake of probe substrate in HEK293 cells expressing respective transporters. The data are means \pm SDs $(n=3)$.

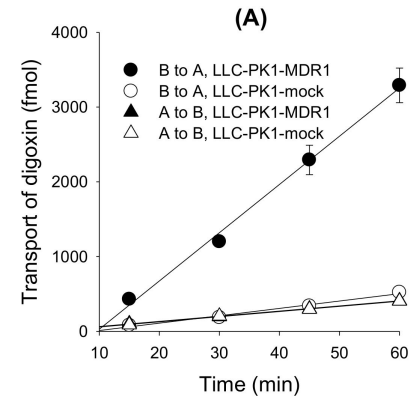

(D)

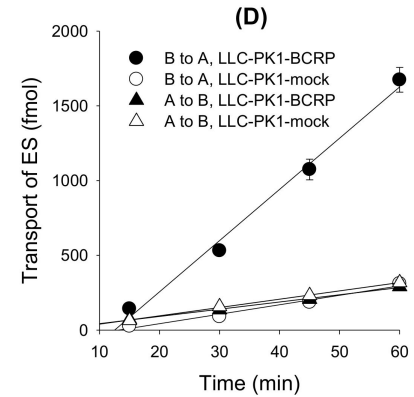

(B)

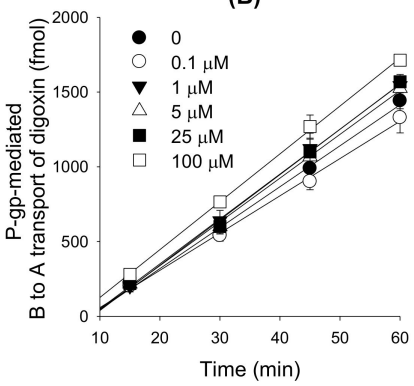

(E)

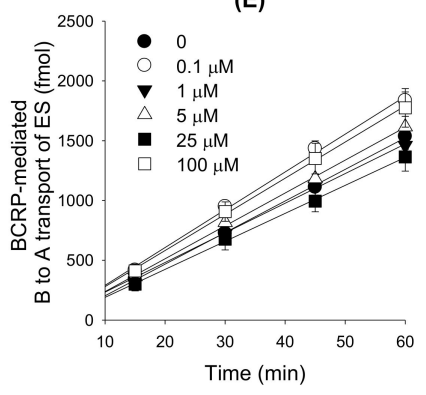

(C)

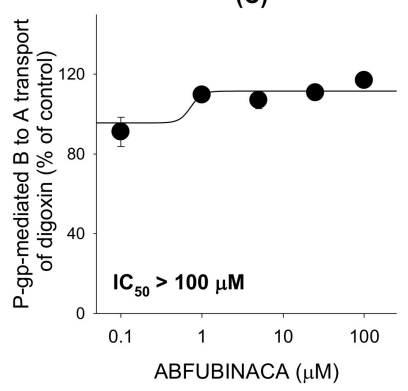

(F)

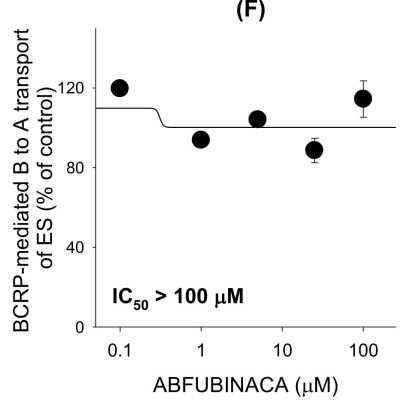

Figure 6. The inhibitory effects of AB-FUBINACA $(0.1-100 \mu \mathrm{M})$ on the P-glycoprotein (P-gp)- and breast cancer resistance protein (BCRP)-mediated basal to apical (B to $\mathrm{A}$ ) transport rate of digoxin and 
estrone-3-sulfate (ES), respectively. (A) B to A and A to B transport of $0.1 \mu \mathrm{M}[3-\mathrm{H}]$ digoxin was measured for $60 \mathrm{~min}$ in LLC-PK1-MDR1 cells and LLC-PK1-mock cells. (B) P-gp-mediated B to A transport of [3-H]digoxin was measure for $60 \mathrm{~min}$ in the presence of AB-FUBINACA $(0,0.1,1,5,25$ and $100 \mu \mathrm{M})$. P-gp-mediated B to A transport of digoxin was calculated by subtracting the B to A transport of digoxin in LLC-PK1-mock cells from the B to A transport of digoxin in LLC-PK1-MDR1 cells. (C) Effect of AB-FUBINACA on the P-gp-mediated B to A transport rate of digoxin was shown in a concentration range of 0.1-100 $\mu \mathrm{M}$ AB-FUBINACA. (D) B to A and A to B transport of $0.1 \mu \mathrm{M}$ [3-H]ES was measured for $60 \mathrm{~min}$ in LLC-PK1-BCRP cells and LLC-PK1-mock cells. (E) BCRP-mediated B to A transport of [3-H]ES was measured for $60 \mathrm{~min}$ in the presence of AB-FUBINACA $(0,0.1,1,5,25$, $100 \mu \mathrm{M})$. BCRP-mediated B to A transport of ES was calculated by subtracting the B to A transport of ES in LLC-PK1-mock cells from the B to A transport of ES in LLC-PK1-BCRP cells. (F) Effect of AB-FUBINACA on the BCRP-mediated $\mathrm{B}$ to A transport rate of ES was shown in a concentration range of $0.1-100 \mu \mathrm{M}$ AB-FUBINACA. The data are means \pm SDs $(n=3)$.

Of the eight transporters tested, the OCT2 and OATP1B1 transporters (inhibited by AB-FUBINACA) were subjected to enzyme kinetic studies to determine the modes of inhibition and the $K_{i}$ values. A Lineweaver-Burk plot of the inhibitory effect of AB-FUBINACA on OCT2-mediated MPP ${ }^{+}$uptake revealed mixed inhibition and a $K_{i}$ value of $54.2 \mu \mathrm{M}$ (Figure 7A and Table 3). AB-FUBINACA competitively inhibited OATP1B1-mediated ES uptake with a $K_{i}$ value of $94.4 \mu \mathrm{M}$ (Figure 7B and Table 3).

(A) OCT2

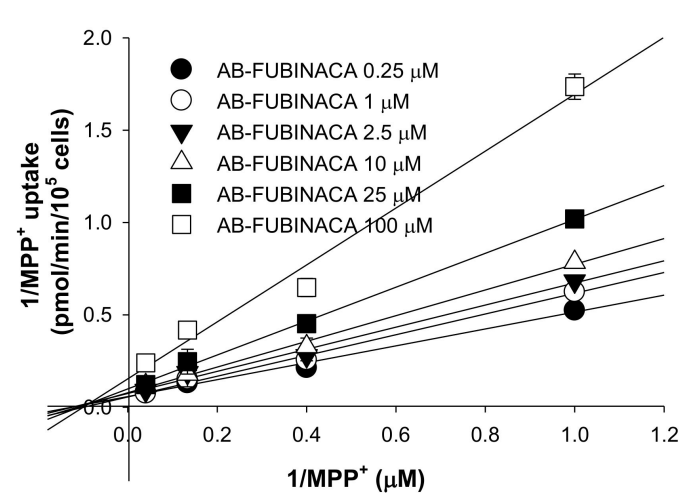

(B) OATP1B1

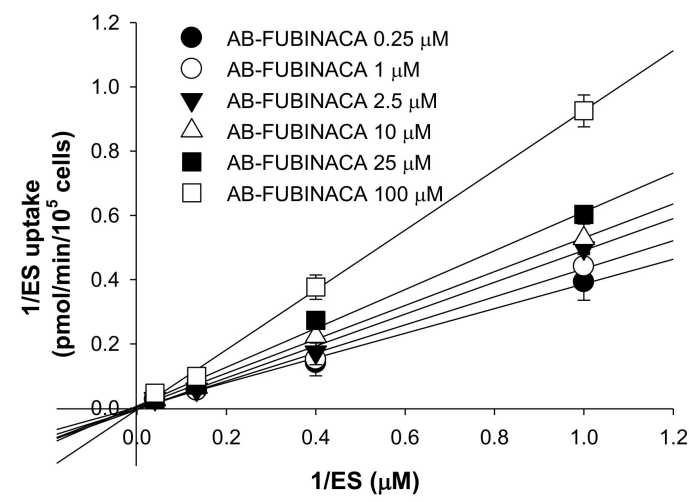

Figure 7. Lineweaver-Burk plots of the inhibitory effects of AB-FUBINACA $(0.25-100 \mu \mathrm{M})$ on $(\mathbf{A})$ OCT2-mediated $\left[{ }^{3} \mathrm{H}\right] \mathrm{MPP}^{+}$uptake and (B) OATP1B1-mediated ES uptake by HEK293-OCT2 and -OATP1B1 cells, respectively, in the presence of various concentrations of $\left[{ }^{3} \mathrm{H}\right] \mathrm{MPP}^{+}$or $\left[{ }^{3} \mathrm{H}\right] \mathrm{ES}(1,2.5$, 7.5 , and $25 \mu \mathrm{M})$. Each symbol represents a concentration of AB-FUBINACA. The data are means \pm SDs $(n=3)$.

Table 3. Enzyme kinetic parameters reflecting the inhibitory potential of AB-FUBINACA in the context of drug transporters.

\begin{tabular}{ccc}
\hline Transporter & $\boldsymbol{K}_{\mathbf{i}}(\boldsymbol{\mu M})$ & Inhibition Mode \\
\hline OCT2 & 54.2 & Mixed \\
OATP1B1 & 94.4 & Competitive \\
\hline
\end{tabular}

\section{Discussion}

AB-FUBINACA competitively inhibited CYP2C8-catalyzed amodiaquine $N$-de-ethylation and CYP2C9-mediated diclofenac 4'-hydroxylation with $K_{i}$ values of 19.9 and $13.1 \mu \mathrm{M}$, respectively: other synthetic cannabinoids including AM-2201, EAM-2201, and MAM-2201 potently inhibited CYP2C8-catalyzed amodiaquine $N$-de-ethylation $\left(K_{i}, 0.54-2.1 \mu \mathrm{M}\right)$ and CYP2C9-mediated diclofenac $4^{\prime}$-hydroxylation $\left(K_{\mathrm{i}}, 3.0-5.6 \mu \mathrm{M}\right)$ by ultrapooled human liver microsomes [27-29]. AB-FUBINACA 
exhibited mixed inhibition of CYP2B6-mediated bupropion hydroxylation with a $K_{i}$ of $15.0 \mu \mathrm{M}$. THC, cannabidiol, and cannabinol inhibited 7-benzoxyresorufin $O$-debenzylase activity in the mixed mode with $K_{\mathrm{i}}$ values of $2.81,0.694$, and $2.55 \mu \mathrm{M}$, respectively, as revealed by the recombinant human CYP2B6 enzyme assay [21]. AB-FUBINACA competitively inhibited CYP2C19-mediated [S]-mephenytoin $4^{\prime}$-hydroxylation with a $K_{i}$ of $6.3 \mu \mathrm{M}$ (Figure 3), but EAM-2201 time-dependently inhibited CYP2C19-mediated [S]-mephenytoin $4^{\prime}$-hydroxylation by human liver microsomes with $K_{i}$ value of $3.8 \mu \mathrm{M}$ and $k_{\text {inact }}$ of $0.0264 \mathrm{~min}^{-1}$ [29]. AB-FUBINACA competitively inhibited CYP2D6-mediated bufuralol 1'-hydroxylation with a $K_{i}$ value of $20.8 \mu \mathrm{M}$, and cannabidiol inhibited CYP2D6-catalyzed dextromethorphan $O$-demethylation by human liver microsomes with a $K_{i}$ value of $2.42 \mu \mathrm{M}[22]$.

For accurate clinical prediction of AB-FUBINACA-induced DDI using in vitro data, the AB-FUBINACA pharmacokinetics in humans (including plasma concentrations, extents of protein binding, and tissue distributions) are necessary. However, none of AB-FUBINACA absorption, distribution, or excretion has been studied in humans or animals. A few reports on AB-FUBINACA concentrations in blood, urine, and oral fluids of drug abusers have appeared; the serum AB-FUBINACA concentration was $15 \mathrm{nM}$ in a healthy 24-year-old man after ingestion of two drops of e-cigarette fluid containing AB-FUBINACA [35] and the post-mortem level of AB-FUBINACA in the femoral blood of a 35-year-old man who engaged in polysubstance abuse was $5.4 \mathrm{nM}$ [36]. The concentrations of AB-FUBINACA in 5 of 70 oral fluid samples collected from 13 subjects were 2.2-106 nM [37]. The extent of AB-FUBINACA $(10 \mu \mathrm{M})$ binding to plasma proteins was $99.7 \pm 0.03 \%$ in our laboratory. Using the basic model of reversible CYP inhibition [38], the predicted ratio of the drug area under the plasma concentration curve (AUC) was less than 1.001. As an AUC change predictive of a significant DDI should exceed 1.02 according to the FDA guideline [34], AB-FUBINCA may not engage in clinically significant DDIs mediated by CYP2B6, CYP2C8, CYP2C9, CYP2C19, or CYP2D6; all were reversibly inhibited by AB-FUBINACA.

AM-2201 $\left(K_{\mathrm{i}}, 4.0 \mu \mathrm{M}\right)$, MAM-2201 $\left(K_{\mathrm{i}}, 5.4 \mu \mathrm{M}\right), \mathrm{EAM}-2201\left(K_{i}, 4.1 \mu \mathrm{M}\right.$ and $\left.k_{\text {inact }}, 0.0250 \mathrm{~min}^{-1}\right)$, and APINACA $\left(K_{i}, 4.5 \mu \mathrm{M} ; k_{\text {inact }}, 0.04686 \mathrm{~min}^{-1}\right)$ inhibited CYP3A4-catalyzed midazolam $1^{\prime}$-hydroxylation in human liver microsomes [27-30], but AB-FUBINACA did not inhibit the CYP3A4, CYP1A2, and CYP2A6 activities of such microsomes (Figure 2).

AB-FUBINACA negligibly inhibited the UGT1A1, UGT1A3, UGT1A4, UGT1A6, UGT1A9, and UGT2B7 activities of human liver microsomes, suggesting that the risk of clinical DDIs between AB-FUBINACA and the UGT1A1, UGT1A3, UGT1A4, UGT1A6, UGT1A9, and UGT2B7 metabolizing enzymes is remote. However, EAM-2201, MAM-2201, and AM-2201 competitively inhibited UGT1A3-mediated chenodeoxycholic acid 24-acyl- $\beta$-glucuronidation with $K_{i}$ values of 2.7, 4.3, and $5.0 \mu \mathrm{M}$, respectively, and APINACA noncompetitively inhibited UGT1A9-mediated mycophenolic acid glucuronidation $\left(K_{\mathrm{i}}, 5.9 \mu \mathrm{M}\right)$ by human liver microsomes [27-30].

AB-FUBINACA weakly inhibited OCT2 and OATP1B1 activities with $K_{\mathrm{i}}$ values of 54.2 and $94.4 \mu \mathrm{M}$, respectively; it poorly inhibited OAT1, OAT3, OCT1, and OATP1B3 activities to $250 \mu \mathrm{M}$; and did not affect the efflux of transporters, P-gp and BCRP to $100 \mu \mathrm{M}$. Thus, AB-FUBINACA is at low risk of interaction with these clinically important drug transporters; AB-FUBINACA present in the blood after drug abuse may not potentiate transporter-mediated toxicity or cause an adverse event.

\section{Materials and Methods}

\subsection{Materials}

AB-FUBINACA was obtained from Cayman Chemical Company (Ann Arbor, MI, USA). Acetaminophen, $\mathrm{N}$-acetylserotonin, alamethicin, chenodeoxycholic acid, coumarin, 7-hydroxycoumarin, magnolol, midazolam, mycophenolic acid, naloxone, naloxone 3- $\beta$-D-glucuronide, NADPH, phenacetin, quindine, rifampin, trifluoperazine, Trizma base, uridine 5'-diphosphoglucuronoic acid (UDPGA), verapamil, sodium dodecyl sulfate (SDS), and Hank's balanced salt solution (HBSS) were the products 
of Sigma-Aldrich (St. Louis, MO, USA). ${ }^{13} \mathrm{C}_{2},{ }^{15} \mathrm{~N}$-acetaminophen, bufuralol, $\mathrm{N}$-desethylamodiaquine, 1'-hydroxybufuralol, $\mathrm{d}_{9}-1^{\prime}$-hydroxybufuralol, 4'-hydroxydiclofenac, 4'-hydroxymephenytoin, 1'-hydroxymidazolam, [S]-mephenytoin, Dulbecco's modified Eagle's medium (DMEM), medium 199, fetal bovine serum (FBS), collagen-coated 24-transwell plates, poly-D-lysine-coated 96-well plates, LLC-PK1-MDR1 cells (LLC-PK1 cells stably expressing P-gp), LLC-PK1-mock cells, HEK293 cells transiently overexpressing the OCT1, OCT2, OAT1, OAT3, OATP1B1, and OATP1B3 transporters (HEK293-OCT1, -OCT2, -OAT1, -OAT3, -OATP1B1, and -OATP1B3 cells, respectively), and HEK293-mock cells were purchased from Corning Life Sciences (Woburn, MA, USA). LLC-PK1-BCRP cells (LLC-PK1 cells stably expressing BCRP) were obtained from Dr. A.H. Schinkel (Netherlands Cancer Institute, Amsterdam, the Netherlands). $\left[{ }^{3} \mathrm{H}\right]$ Methyl-4-phenylpyridinium (2.9 TBq/mmol), $\left[{ }^{3} \mathrm{H}\right]$ para-aminohippuric acid $(0.13 \mathrm{TBq} / \mathrm{mmol}),\left[{ }^{3} \mathrm{H}\right]$ estrone-3-sulfate $(2.12 \mathrm{TBq} / \mathrm{mmol})$, $\left[{ }^{3} \mathrm{H}\right]$ estradiol-17 $\beta$-D-glucuronide $(2.22 \mathrm{TBq} / \mathrm{mmol}),\left[{ }^{3} \mathrm{H}\right]$ digoxin $(1.103 \mathrm{TBq} / \mathrm{mmol})$, and Optiphase scintillation cocktail were purchased from Perkin Elmer Inc. (Boston, MA, USA). N-acetylserotonin $\beta$-D-glucuronide, chenodeoxycholic acid 24-acyl- $\beta$-glucuronide, diclofenac, mycophenolic acid $\beta$-D-glucuronide, and SN-38 glucuronide were obtained from Toronto Research Chemicals (Toronto, ON, Canada). SN-38 was the product of Santa Cruz Biotechnology (Dallas, TX, USA). Acetonitrile, methanol, and water (LC-MS grade) were obtained from Fisher Scientific Co. (Fair Lawn, NJ, USA). All other chemicals were of the highest quality available.

\subsection{Inhibitory Effect of AB-FUBINACA on Eight Major CYP Activities in Human Liver Microsomes}

The inhibitory potentials ( $\mathrm{IC}_{50}$ values) of AB-FUBINACA on CYP 1A2, 2A6, 2B6, 2C8, 2C9, $2 \mathrm{C} 19,2 \mathrm{D} 6$, and 3A4 activities in pooled human liver microsomes were evaluated using a slight modification of our previously described method that employed a cocktail of CYP substrates, followed by LC-MS/MS [27-30]. The incubation mixtures were prepared in total volumes of $100 \mu \mathrm{L}$ as follows: $50 \mathrm{mM}$ potassium phosphate buffer ( $\mathrm{pH}$ 7.4), $1.0 \mathrm{mM} \mathrm{NADPH}, 10 \mathrm{mM} \mathrm{MgCl}$, ultrapooled human liver microsomes $(0.2 \mathrm{mg} / \mathrm{mL}$ ), various concentrations of AB-FUBINACA (final concentrations of $0.1-100 \mu \mathrm{M})$, and the CYP enzyme-specific substrates of the cocktail sets A $(2.0 \mu \mathrm{M}$ amodiaquine, $5 \mu \mathrm{M}$ bufuralol, $2.5 \mu \mathrm{M}$ coumarin, $10 \mu \mathrm{M}$ diclofenac, $100 \mu \mathrm{M}$ [S]-mephenytoin, $2.5 \mu \mathrm{M}$ midazolam, and $50 \mu \mathrm{M}$ phenacetin) and B (50 $\mu \mathrm{M}$ bupropion). After $3 \mathrm{~min}$ of pre-incubation at $37^{\circ} \mathrm{C}$, the reaction mixtures were incubated for $15 \mathrm{~min}$ at $37^{\circ} \mathrm{C}$ after addition of NADPH in a shaking water bath. Each reaction was stopped by adding $100 \mu \mathrm{L}$ of ice-cold methanol containing $\mathrm{d}_{9}-1^{\prime}$-hydroxybufuralol (internal standard (IS) for 1-hydroxybupropion, 1'-hydroxybufuralol, $4^{\prime}$-hydroxydiclofenac, 7-hydroxycoumarin, 1'-hydroxymidazolam, and 4'-hydroxymephenytoin) and ${ }^{13} \mathrm{C}_{2},{ }^{15} \mathrm{~N}$-acetaminophen (IS for acetaminophen and $\mathrm{N}$-desethylamodiaquine). The incubation mixtures were centrifuged at $13,000 \times g$ for $8 \mathrm{~min}$ at $4{ }^{\circ} \mathrm{C}$, and $50 \mu \mathrm{L}$ of each supernatant of the A and B sets mixed. Aliquots $(5 \mu \mathrm{L})$ of the diluted supernatants were analyzed by LC-MS/MS. All assays were performed in triplicate, and the averages were used for subsequent calculations.

To measure time-dependent inhibition, human liver microsomes were pre-incubated with various concentrations of AB-FUBINACA (final concentrations of $0.1-100 \mu \mathrm{M}$ ) and NADPH for $30 \mathrm{~min}$ at $37^{\circ} \mathrm{C}$. Next, the reaction mixtures were incubated with the $A$ or $B$ set of $C Y P$ substrates for $15 \mathrm{~min}$ at $37^{\circ} \mathrm{C}$. The control reaction featured the addition of methanol rather than AB-FUBINACA.

An Agilent 6495 triple quadrupole mass spectrometer coupled with an Agilent 1290 Infinity system (Agilent Technologies, Wilmington, DE, USA) was used for LC-MS/MS. Metabolites of the eight CYP substrates were simultaneously separated on an Atlantis dC18 column $(3 \mu \mathrm{m}, 2.1 \mathrm{~mm}$ internal diameter $\times 100 \mathrm{~mm}$; Waters Co., Milford, MA, USA) using a gradient elution of $5 \%$ methanol in $0.1 \%$ formic acid (MP A) and $95 \%$ methanol in $0.1 \%$ formic acid (MP B) at a flow rate of $0.3 \mathrm{~mL} / \mathrm{min}$ : $20 \%$ MP B for $0.5 \mathrm{~min}$; 20-95\% MP B for $0.5 \mathrm{~min}$; $95 \%$ MP B for $6 \mathrm{~min}$; $95-20 \%$ MP B for $0.1 \mathrm{~min}$; and $20 \%$ MP B for $3 \mathrm{~min}$. The column and autosampler temperatures were 40 and $4{ }^{\circ} \mathrm{C}$, respectively. The electrospray ionization (ESI) source settings in the positive ion mode were: gas temperature, $200{ }^{\circ} \mathrm{C}$; gas flow, $14 \mathrm{~L} / \mathrm{min}$; nebulizer pressure, $40 \mathrm{psi}$; sheath gas temperature, $380{ }^{\circ} \mathrm{C}$; sheath gas flow, 
$11 \mathrm{~L} / \mathrm{min}$; capillary voltage, $4500 \mathrm{~V}$; and nozzle voltage, $500 \mathrm{~V}$. Quantification of each metabolite was performed in the selected reaction monitoring (SRM) mode: acetaminophen, $m / z$ 152.1 $\rightarrow 110.1$; 7-hydroxycoumarin, $m / z 163.0 \rightarrow 107.0 ;$ 4-hydroxybupropion, $m / z$ 256.1 $\rightarrow 238.0$; $N$-desethylamodiaquine, $m / z 328.1 \rightarrow 283.0 ; 4^{\prime}$-hydroxydiclofenac, $m / z$ 312.0 $\rightarrow 231.0 ; 4^{\prime}$-hydroxymephenytoin, $m / z 235.2 \rightarrow 150.0$; $1^{\prime}$-hydroxybufuralol, $m / z \quad 278.3 \rightarrow 187.0 ; \quad 1^{\prime}$-hydroxymidazolam, $m / z \quad 342.1 \rightarrow 324.1, \quad{ }^{13} C_{2}$ ， ${ }^{15} \mathrm{~N}$-acetaminophen (IS), $m / z \quad 155.1 \rightarrow 111.1$ and $\mathrm{d}_{9}-1^{\prime}$-hydroxybufuralol (IS), $m / z \quad 287.0 \rightarrow 187.0$. The data were processed using MassHunter software ver. B.07.00 (Agilent Technologies). Typical SRM chromatograms and method validation data of eight CYP metabolites are shown in Supplementary Figure S1 and Table S1, respectively.

\subsection{Inhibitory Effects of AB-FUBINACA on Six Major UGT Activities}

The inhibitory effects of AB-FUBINACA on UGT1A1, UGT1A3, UGT1A4, UGT1A6, UGT1A9, and UGT2B7 were evaluated using our previously described LC-MS/MS method after incubation of ultrapooled human liver microsomes with a cocktail of UGT substrates [27-30]. Each incubation mixture was prepared in a final volume of $100 \mu \mathrm{L}$ as follows: ultrapooled human liver microsomes (0.2 mg/mL), $5 \mathrm{mM}$ UDPGA, $10 \mathrm{mM}$ magnesium chloride, alamethicin $(25 \mu \mathrm{g} / \mathrm{mL}), 50 \mathrm{mM}$ Tris buffer ( $\mathrm{pH}$ 7.4), various concentrations of AB-FUBINACA in methanol (final concentrations of 0.1-100 $\mu \mathrm{M}$, methanol $<0.5 \% v / v)$ and the UGT enzyme-specific substrates of the cocktail sets A $(0.5 \mu \mathrm{M}$ SN-38, $2 \mu \mathrm{M}$ chenodeoxycholic acid, and $0.5 \mu \mathrm{M}$ trifluoperazine) and B (1 $\mu \mathrm{M} N$-acetylserotonin, $0.2 \mu \mathrm{M}$ mycophenolic acid, and $1 \mu \mathrm{M}$ naloxone). The reactions were initiated by adding UDPGA, and incubations continued for $60 \mathrm{~min}$ at $37^{\circ} \mathrm{C}$ in a shaking water bath. The reactions were terminated by adding $50 \mu \mathrm{L}$ of ice-cold acetonitrile containing propofol glucuronide (IS for chenodeoxycholic acid 24-acyl- $\beta$-glucuronide and mycophenolic acid glucuronide) and meloxicam (IS for SN-38 glucuronide, trifluoperazine glucuronide, $N$-acetylserotonin $\beta$-D-glucuronide, and naloxone 3- $\beta$-D-glucuronide). The incubation mixtures were centrifuged at $13,000 \times g$ for $8 \mathrm{~min}$ at $4{ }^{\circ} \mathrm{C}$. Then, $50 \mu \mathrm{L}$-aliquots of each supernatant of the A and B set were mixed and aliquots $(5 \mu \mathrm{L})$ subjected to LC-MS/MS. All assays were performed in triplicate, and the averages were used in calculations.

The six UGT metabolites were simultaneously separated on an Atlantis dC18 column $(3 \mu \mathrm{m}, 2.1 \mathrm{~mm}$ internal diameter $\times 100 \mathrm{~mm}$ ) via gradient elution of $5 \%$ acetonitrile in $0.1 \%$ formic acid (MP A) and $95 \%$ acetonitrile in $0.1 \%$ formic acid (MP B) at a flow rate of $0.3 \mathrm{~mL} / \mathrm{min}$ : $10 \% \mathrm{MP}$ B for $1 \mathrm{~min} ; 10-50 \% \mathrm{MP} \mathrm{B}$ for $1 \mathrm{~min}$; $50-95 \%$ MP B for $1 \mathrm{~min}$; 95\% MP B for $2 \mathrm{~min}$; 95-5\% MP B for $0.1 \mathrm{~min}$; and 5\% MP B for $2.9 \mathrm{~min}$. The ESI source settings in both the positive and negative ion modes were: gas temperature, $200{ }^{\circ} \mathrm{C}$; gas flow, $14 \mathrm{~L} / \mathrm{min}$; nebulizer pressure, $40 \mathrm{psi}$; sheath gas temperature, $380^{\circ} \mathrm{C}$; sheath gas flow, $11 \mathrm{~L} / \mathrm{min}$; capillary voltage, $4500 \mathrm{~V}$; and nozzle voltage, $500 \mathrm{~V}$. Each metabolite was quantified via SRM in the negative ion mode (chenodeoxycholic acid 24 -acyl- $\beta$-glucuronide, $m / z$ 567.1 $\rightarrow 391$.2; mycophenolic acid glucuronide, $m / z 495.0 \rightarrow 319.0$; propofol glucuronide (IS), $m / z 353.0 \rightarrow 177.0)$ and in the positive ion mode (SN-38 glucuronide, $m / z 568.9 \rightarrow 392.9 ;$ trifluoperazine glucuronide, $m / z$ 583.9 $\rightarrow 407.9 ; N$-acetylserotonin $\beta$-D-glucuronide, $m / z \quad 394.9 \rightarrow 219.0 ;$ naloxone $3-\beta$-D-glucuronide, $m / z$ 503.9 $\rightarrow 309.9 ;$ meloxicam (IS), $m / z \quad 351.9 \rightarrow 115.0)$. Typical SRM chromatograms and method validation data of six UGT metabolites are shown in Supplementary Figure S2 and Table S1, respectively.

\subsection{Enzyme Kinetic Analysis of the Inhibition by AB-FUBINACA of Five CYP Enzyme Activities in Human Liver Microsomes}

To determine the enzyme kinetic parameters and modes of inhibition of CYP2B6, CYP2C8, CYP2C9, CYP2C19, and CYP2D6 by AB-FUBINACA, various concentrations of AB-FUBINACA (final concentrations of 2-60 $\mu \mathrm{M}$ ) and bupropion (final concentrations of 10-100 $\mu \mathrm{M}$ for CYP2B6), amodiaquine (1-8 $\mu \mathrm{M}$ for CYP2C8), diclofenac (2-20 $\mu \mathrm{M}$ for CYP2C9), [S]-mephenytoin (20-160 $\mu \mathrm{M}$ for CYP2C19), and bufuralol (2.5-20 $\mu \mathrm{M}$ for CYP2D6) were incubated with human liver microsomes $(0.15 \mathrm{mg} / \mathrm{mL})$, $10 \mathrm{mM} \mathrm{MgCl} 2,5 \mathrm{mM}$ NADPH, and $50 \mathrm{mM}$ phosphate buffer (pH 7.4) in a total volume of $100 \mu \mathrm{L}$ for $30 \mathrm{~min}$ at $37^{\circ} \mathrm{C}$. The reaction was stopped by adding $100 \mu \mathrm{L}$ of ice-cold acetonitrile containing 
$\mathrm{d}_{9}-1^{\prime}$-hydroxybufuralol (IS for 1-hydroxybupropion, 1'-hydroxybufuralol, 4'-hydroxydiclofenac, and $4^{\prime}$-hydroxymephenytoin) or ${ }^{13} \mathrm{C}_{2},{ }^{15} \mathrm{~N}$-acetaminophen (IS for $\mathrm{N}$-desethylamodiaquine), and the mixtures centrifuged at $13,000 \times g$ for $4 \mathrm{~min}$. Next, $50 \mu \mathrm{L}$ of each supernatant was diluted with $50 \mu \mathrm{L}$ of water, and aliquots $(5 \mu \mathrm{L})$ analyzed by LC-MS/MS.

\subsection{Inhibitory Effects of AB-FUBINACA on the Transport Activities of OCTs, OATs, OATPs, P-gp, and BCRP}

HEK293 cells overexpressing OCT1, OCT2, OAT1, OAT3, OATP1B1, and OATP1B3 transporters and HEK293-mock cells were seeded into poly-D-lysine-coated 96-well plates at $10^{5}$ cells/well and cultured in DMEM supplemented with 10\% FBS, $5 \mathrm{mM}$ nonessential amino acids, and $2 \mathrm{mM}$ sodium butyrate for $24 \mathrm{~h}$ at $37{ }^{\circ} \mathrm{C}$ in a humidified atmosphere under $8 \% \mathrm{CO}_{2}$. After $24 \mathrm{~h}$, the medium was discarded and the attached cells were washed with pre-warmed HBSS and pre-incubated for $10 \mathrm{~min}$ in pre-warmed HBSS at $37^{\circ} \mathrm{C}$.

To examine the effects of AB-FUBINACA on the activities of six uptake transporters, the probe uptakes into HEK293 cells overexpressing the transporters were measured in the presence of AB-FUBINACA $(0-250 \mu \mathrm{M})$ for $5 \mathrm{~min}$. The concentrations and probe substrates were as follows: $0.1 \mu \mathrm{M}\left[{ }^{3} \mathrm{H}\right] \mathrm{MPP}^{+}$(for OCT1 and OCT2), $0.1 \mu \mathrm{M}\left[{ }^{3} \mathrm{H}\right] \mathrm{PAH}$ (for OAT1), $0.1 \mu \mathrm{M}\left[{ }^{3} \mathrm{H}\right] \mathrm{ES}$ (for OAT3 and OATP1B1), and $0.1 \mu \mathrm{M}\left[{ }^{3} \mathrm{H}\right] \mathrm{EG}$ (for OATP1B3). After $5 \mathrm{~min}$, the incubation medium was discarded and the attached cells were washed three-times with ice-cold HBSS (200 $\mu \mathrm{L}$ each time) and lysed with $10 \%$ SDS solution $(50 \mu \mathrm{L})$. The lysates were mixed thoroughly with Optiphase scintillation cocktail $(250 \mu \mathrm{L})$ and radioactivity measured using a liquid scintillation counter. The uptake of probe into HEK293-mock cells was measured using the same protocol. The transporter-mediated uptake of probe was calculated by subtracting the uptake of HEK293-mock cells from the uptake of HEK293 cells overexpressing the OCT1, OCT2, OAT1, OAT3, OATP1B1, and OATP1B3 transporters.

LLC-PK1-MDR1, LLC-PK1-BCRP, and LLC-PK1-mock cells were grown in tissue culture flasks in medium 199 supplemented with $10 \%$ FBS and $50 \mu \mathrm{g} / \mathrm{mL}$ gentamycin, seeded into 24-well transwell plates at $10^{5}$ cells/well for 5 days to TEER values over $450 \Omega \cdot \mathrm{cm}^{2}$. The B to A transport of digoxin by LLC-PK1-MDR1 and -mock cells was initiated by adding $0.8 \mathrm{~mL}$ of HBSS containing $0.1 \mu \mathrm{M}$ $\left[{ }^{3} \mathrm{H}\right]$ digoxin and AB-FUBINACA $(0-100 \mu \mathrm{M})$ on the basal side and $0.4 \mathrm{~mL}$ of fresh HBSS on the apical side of the transwell. Every $15 \mathrm{~min}$ for $1 \mathrm{~h}, 0.3 \mathrm{~mL}$ aliquots were taken from the apical side and $0.3 \mathrm{~mL}$ fresh prewarmed HBSS added. The B to A transport of ES in LLC-PK1-BCRP and -mock cells was measured using the same protocol in the presence of $0.1 \mu \mathrm{M}\left[{ }^{3} \mathrm{H}\right] \mathrm{ES}$ and AB-FUBINACA $(0-100 \mu \mathrm{M})$ on the basal side. The A to B transport of digoxin by LLC-PK1-MDR1 and -mock cells was initiated by adding $0.4 \mathrm{~mL}$ of HBSS containing $0.1 \mu \mathrm{M}\left[{ }^{3} \mathrm{H}\right]$ digoxin on the apical side and $0.8 \mathrm{~mL}$ of fresh HBSS on the basal side of the transwell. Every $15 \mathrm{~min}$ for $1 \mathrm{~h}$, the transwell was moved to another well containing $0.8 \mathrm{~mL}$ fresh prewarmed HBSS. The A to B transport of ES by LLC-PK1-BCRP and -mock cells was measured using the same protocol in the presence of $0.1 \mu \mathrm{M}\left[{ }^{3} \mathrm{H}\right] \mathrm{ES}$ on the apical side. Aliquots $(100 \mu \mathrm{L})$ of transported samples were mixed with $200 \mu \mathrm{L}$ of Optiphase scintillation cocktail and radioactivity was measured with a liquid scintillation counter. The B to A transports of digoxin and ES (mediated by P-gp and BCRP, respectively) were calculated by subtracting the probe transport of LLC-PK1-mock cells from those of LLC-PK1-MDR1 and -BCRP cells. The P-gp-mediated B to A transport rate of digoxin and the BCRP-mediated $\mathrm{B}$ to a transport rate of ES were calculated from the slope of the B to A transports of digoxin and ES versus time profile. Efflux ratio was calculated by dividing $\mathrm{B}$ to $\mathrm{A}$ transport ratio of probe substrate by A to B transport rate in LLC-PK1-MDR1, LLC-PK1-BCRP, and LLC-PK1-mock cells and net efflux ratio was calculate by dividing efflux ratio of probe substrate in LLC-PK1-MDR1 or LLC-PK1-BCRP by efflux ratio in LLC-PK1-mock cells.

\subsection{Data Analysis}

The inhibition data were fitted to an inhibitory effect model using Sigma Plot ver. 12.0 (Systat Software Inc., San Jose, CA, USA) to obtain the $\mathrm{IC}_{50}$ values (the half-maximal inhibitory concentrations) of AB-FUBINACA [30]. $K_{i}$ (inhibition constant) values of AB-FUBINACA and the mode of inhibition 
were calculated/derived by drawing Lineweaver-Burk plots [39] using Enzyme Kinetics ver. 1.1 (Systat Software, Inc.).

\section{Conclusions}

The in vitro inhibitory effects of AB-FUBINACA on eight major clinically important CYP and six UGT enzymes of ultrapooled human liver microsomes and on six solute carrier transporters and two efflux transporters using a transporter expression system were investigated for the first time to predict the drug interaction potential of AB-FUBINACA via the modulation of drug-metabolizing enzymes and transporters. AB-FUBINACA moderately inhibited CYP2B6, CYP2C8, CYP2C9, CYP2C19, CYP2D6, OCT2, and OATP1B1 activities with $K_{\mathrm{i}}$ values of 15.0, 19.9, 13.1, 6.3, 20.8, 54.2, and 94.4 $\mu \mathrm{M}$, respectively. Although in vitro inhibition of CYP, UGT, and transporter activities does not necessarily translate into significant DDIs using a basic prediction model, it is necessary to evaluate the in vivo potential of AB-FUBINACA to cause DDIs via the inhibition of CYP2B6, CYP2C8, CYP2C9, CYP2C19, CYP2D6, OCT2, and OATP1B1 activities.

Supplementary Materials: The following are available online, Figure S1: SRM chromatograms of CYP metabolites formed from human liver microsomal incubation of eight CYP cocktail substrates with NADPH and two IS, Figure S2: SRM chromatograms of UGT metabolites formed from human liver microsomal incubation of six UGT cocktail substrates with UDPGA and two IS, Table S1: Concentration ranges and correlation coefficients of the calibration curves and precision (coefficient of variation, CV) and accuracy values for CYP and UGT metabolites.

Author Contributions: Conceptualization, S.K., D.K.K., I.-S.S. and H.S.L.; investigation, S.K., D.K.K., Y.S. and J.-H.J.; writing — original draft preparation, S.K. and D.K.K.; writing-review and editing, I.-S.S. and H.S.L.; supervision, H.S.L.; funding acquisition, I.-S.S. and H.S.L. All authors have read and agreed to the published version of the manuscript.

Funding: This work was supported by the National Research Foundation of Korea (NRF) grant funded by the Korea government (MSIT) (No. 2015M3A9E1028325, 2020R1A2C2008461, and 2020R1A5A2017323).

Conflicts of Interest: The authors declare no conflict of interest.

\section{References}

1. Le Boisselier, R.; Alexandre, J.; Lelong-Boulouard, V.; Debruyne, D. Focus on cannabinoids and synthetic cannabinoids. Clin. Pharmacol. Ther. 2017, 101, 220-229. [CrossRef] [PubMed]

2. Synthetic cannabinoids in Europe. Available online: http://emcdda.europa.eu/topics/pods/syntheticcannabinoids (accessed on 6 June 2017).

3. Uchiyama, N.; Matsuda, S.; Wakana, D.; Kikura-Hanajiri, R.; Goda, Y. New cannabimimetic indazole derivatives, $N$-(1-amino-3-methyl-1-oxobutan-2-yl)-1-pentyl-1H-indazole-3-carboxamide (AB-PINACA) and N-(1-amino-3-methyl-1-oxobutan-2-yl)-1-(4-fluorobenzyl)-1H-indazole-3-carboxamide (AB-FUBINACA) identified as designer drugs in illegal products. Forensic Toxicol. 2013, 31, 93-100.

4. Kong, T.Y.; Kim, J.H.; Kim, D.K.; Lee, H.S. Synthetic cannabinoids are substrates and inhibitors of multiple drug-metabolizing enzymes. Arch. Pharm. Res. 2018, 41, 691-710. [CrossRef]

5. Canazza, I.; Ossato, A.; Vincenzi, F.; Gregori, A.; Rosa, F.; Nigro, F.; Rimessi, A.; Pinton, P.; Varani, K.; Borea, P.; et al. Pharmaco-toxicological effects of the novel third-generation fluorinate synthetic cannabinoids, 5F-ADBINACA, AB-FUBINACA, and STS-135 in mice. In vitro and in vivo studies. Hum. Psychopharmacol. 2017, 32, 2601. [CrossRef] [PubMed]

6. Trecki, J.; Gerona, R.R.; Schwartz, M.D. Synthetic Cannabinoid-Related Illnesses and Deaths. N. Engl. J. Med. 2015, 373, 103-107. [CrossRef]

7. Rosado, T.; Goncalves, J.; Luis, A.; Malaca, S.; Soares, S.; Vieira, D.N.; Barroso, M.; Gallardo, E. Synthetic cannabinoids in biological specimens: A review of current analytical methods and sample preparation techniques. Bioanalysis 2018, 10, 1609-1623. [CrossRef] [PubMed]

8. Tai, S.; Fantegrossi, W.E. Pharmacological and toxicological effects of synthetic cannabinoids and their metabolites. Curr. Top. Behav. Neurosci. 2017, 32, 249-262. [PubMed]

9. Vikingsson, S.; Green, H.; Brinkhagen, L.; Mukhtar, S.; Josefsson, M. Identification of AB-FUBINACA metabolites in authentic urine samples suitable as urinary markers of drug intake using liquid chromatography quadrupole tandem time of flight mass spectrometry. Drug Test. Anal. 2016, 8, 950-956. [CrossRef] [PubMed] 
10. Takayama, T.; Suzuki, M.; Todoroki, K.; Inoue, K.; Min, J.Z.; Kikura-Hanajiri, R.; Goda, Y.; Toyo'oka, T. UPLC/ESI-MS/MS-based determination of metabolism of several new illicit drugs, ADB-FUBINACA, AB-FUBINACA, AB-PINACA, QUPIC, 5FQUPIC and $\alpha$-PVT, by human liver microsome. Biomed Chromatogr. 2014, 28, 831-838. [CrossRef]

11. Castaneto, M.S.; Wohlfarth, A.; Pang, S.; Zhu, M.; Scheidweiler, K.B.; Kronstrand, R.; Huestis, M.A. Identification of AB-FUBINACA metabolites in human hepatocytes and urine using high-resolution mass spectrometry. Forensic Toxicol. 2015, 33, 295-310. [CrossRef]

12. Thomsen, R.; Nielsen, L.M.; Holm, N.B.; Rasmussen, H.B.; Linnet, K. Synthetic cannabimimetic agents metabolized by carboxylesterases. Drug Test. Anal. 2015, 7, 565-576. [CrossRef] [PubMed]

13. Kong, T.Y.; Kim, J.H.; Kim, J.Y.; In, M.K.; Choi, K.H.; Kim, H.S.; Lee, H.S. Rapid analysis of drugs of abuse and their metabolites in human urine using dilute and shoot liquid chromatography-tandem mass spectrometry. Arch. Pharm. Res. 2017, 40, 180-196. [CrossRef] [PubMed]

14. Salomone, A.; Palamar, J.J.; Gerace, E.; Di Corcia, D.; Vincenti, M. Hair Testing for Drugs of abuse and new psychoactive substances in a high-risk population. J. Anal. Toxicol. 2017, 41, 376-381. [CrossRef] [PubMed]

15. Shin, Y.; Kong, T.Y.; Cheong, J.C.; Kim, J.Y.; Lee, J.I.; Lee, H.S. Simultaneous determination of 75 abuse drugs including amphetamines, benzodiazepines, cocaine, opioids, piperazines, zolpidem and metabolites in human hair samples using liquid chromatography-tandem mass spectrometry. Biomed. Chromatogr. 2019, 33, e4600. [CrossRef] [PubMed]

16. Foti, R.S.; Dalvie, D.K. Cytochrome P450 and Non-Cytochrome P450 Oxidative Metabolism: Contributions to the Pharmacokinetics, Safety, and Efficacy of Xenobiotics. Drug Metab. Dispos. 2016, 44, 1229-1245. [CrossRef] [PubMed]

17. Cerny, M.A. Prevalence of Non-Cytochrome P450-Mediated Metabolism in Food and Drug AdministrationApproved Oral and Intravenous Drugs: 2006-2015. Drug Metab. Dispos. 2016, 44, 1246-1252. [CrossRef] [PubMed]

18. Mao, Q.; Lai, Y.; Wang, J. Drug transporters in xenobiotic disposition and pharmacokinetic prediction. Drug Metab. Dispos. 2018, 46, 561-566. [CrossRef] [PubMed]

19. Yamaori, S.; Kushihara, M.; Yamamoto, I.; Watanabe, K. Characterization of major phytocannabinoids, cannabidiol and cannabinol, as isoform-selective and potent inhibitors of human CYP1 enzymes. Biochem. Pharmacol. 2010, 79, 1691-1698. [CrossRef]

20. Yamaori, S.; Ebisawa, J.; Okushima, Y.; Yamamoto, I.; Watanabe, K. Potent inhibition of human cytochrome P450 3A isoforms by cannabidiol: Role of phenolic hydroxyl groups in the resorcinol moiety. Life Sci. 2011, 88, 730-736. [CrossRef]

21. Yamaori, S.; Maeda, C.; Yamamoto, I.; Watanabe, K. Differential inhibition of human cytochrome P450 2A6 and 2B6 by major phytocannabinoids. Forensic Toxicol. 2011, 29, 117-124. [CrossRef]

22. Yamaori, S.; Okamoto, Y.; Yamamoto, I.; Watanabe, K. Cannabidiol, a major phytocannabinoid, as a potent atypical inhibitor for CYP2D6. Drug Metab. Dispos. 2011, 39, 2049-2056. [CrossRef] [PubMed]

23. Yamaori, S.; Koeda, K.; Kushihara, M.; Hada, Y.; Yamamoto, I.; Watanabe, K. Comparison in the in vitro inhibitory effects of major phytocannabinoids and polycyclic aromatic hydrocarbons contained in marijuana smoke on cytochrome P450 2C9 activity. Drug Metab. Pharmacokinet. 2012, 27, 294-300. [CrossRef] [PubMed]

24. Jiang, R.; Yamaori, S.; Okamoto, Y.; Yamamoto, I.; Watanabe, K. Cannabidiol is a potent inhibitor of the catalytic activity of cytochrome P450 2C19. Drug Metab. Pharmacokinet. 2013, 28, 332-338. [CrossRef] [PubMed]

25. Zendulka, O.; Dovrtelova, G.; Noskova, K.; Turjap, M.; Sulcova, A.; Hanus, L.; Jurica, J. Cannabinoids and Cytochrome P450 Interactions. Curr. Drug Metab. 2016, 17, 206-226. [CrossRef]

26. Ashino, T.; Hakukawa, K.; Itoh, Y.; Numazawa, S. Inhibitory effect of synthetic cannabinoids on CYP1A activity in mouse liver microsomes. J. Toxicol. Sci. 2014, 39, 815-820. [CrossRef]

27. Kim, J.H.; Kwon, S.S.; Kong, T.Y.; Cheong, J.C.; Kim, H.S.; In, M.K.; Lee, H.S. AM-2201 Inhibits Multiple Cytochrome P450 and Uridine 5'-Diphospho-Glucuronosyltransferase Enzyme Activities in Human Liver Microsomes. Molecules 2017, 22, 443. [CrossRef]

28. Kong, T.Y.; Kim, J.H.; Kwon, S.S.; Cheong, J.C.; Kim, H.S.; In, M.K.; Lee, H.S. Inhibition of cytochrome P450 and uridine 5'-diphospho-glucuronosyltransferases by MAM-2201 in human liver microsomes. Arch. Pharm. Res. 2017, 40, 727-735. [CrossRef] 
29. Kong, T.Y.; Kwon, S.S.; Cheong, J.C.; Kim, H.S.; Kim, J.Y.; Lee, H.S. In Vitro Inhibitory Effects of Synthetic Cannabinoid EAM-2201 on Cytochrome P450 and UDP-Glucuronosyltransferase Enzyme Activities in Human Liver Microsomes. Molecules 2018, 23, 920. [CrossRef]

30. Kim, S.; Choi, W.G.; Kwon, M.; Lee, S.; Cho, Y.Y.; Lee, J.Y.; Kang, H.C.; Song, I.S.; Lee, H.S. In Vitro Inhibitory Effects of APINACA on Human Major Cytochrome P450, UDP-Glucuronosyltransferase Enzymes, and Drug Transporters. Molecules 2019, 23, 3000. [CrossRef]

31. Tournier, N.; Chevillard, L.; Megarbane, B.; Pirnay, S.; Scherrmann, J.M.; Decleves, X. Interaction of drugs of abuse and maintenance treatments with human P-glycoprotein (ABCB1) and breast cancer resistance protein (ABCG2). Int. J. Neuropsychopharmacol. 2010, 13, 905-915. [CrossRef]

32. Holland, M.L.; Panetta, J.A.; Hoskins, J.M.; Bebawy, M.; Roufogalis, B.D.; Allen, J.D.; Arnold, J.C. The effects of cannabinoids on P-glycoprotein transport and expression in multidrug resistant cells. Biochem. Pharmacol. 2006, 71, 1146-1154. [CrossRef] [PubMed]

33. Wagmann, L.; Maurer, H.H.; Meyer, M.R. Inhibition and stimulation of the human breast cancer resistance protein as in vitro predictor of drug-drug interactions of drugs of abuse. Arch. Toxicol. 2018, 92, 2875-2884. [CrossRef] [PubMed]

34. Meyer, M.R.; Wagmann, L.; Schneider-Daum, N.; Loretz, B.; de Souza Carvalho, C.; Lehr, C.M.; Maurer, H.H. P-glycoprotein interactions of novel psychoactive substances - stimulation of ATP consumption and transport across Caco-2 monolayers. Biochem. Pharmacol. 2015, 94, 220-226. [CrossRef] [PubMed]

35. Lam, R.P.K.; Tang, M.H.Y.; Leung, S.C.; Chong, Y.K.; Tsui, M.S.H.; Mak, T.W.L. Supraventricular tachycardia and acute confusion following ingestion of e-cigarette fluid containing AB-FUBINACA and ADB-FUBINACA: A case report with quantitative analysis of serum drug concentrations. Clin. Toxicol. 2017, 55, 662-667. [CrossRef]

36. Fernandez, D.; Hammer, J.; De Olano, J.; Nelson, L.S.; Hoffman, R.S.; Su, M.K. A synthetic cannabinoid receptor agonist (AB-FUBINACA)-associated fatality. 36th International Congress of the European Association of Poisons Centres and Clinical Toxicologists (EAPCCT) 24-27 May 2016, Madrid, Spain. Clin. Toxicol. 2016, 54,408 .

37. Blandino, V.; Wetzel, J.; Kim, J.; Haxhi, P.; Curtis, R.; Concheiro, M. Oral fluid vs urine analysis to monitor synthetic cannabinoids and classic drugs recent exposure. Curr. Pharm. Biotechnol. 2017, 18, 796-805. [CrossRef]

38. Food and Drug Administration Center for Drug Evaluation and Research. In vitro drug interaction studies-Cytochrome P450 enzyme- and transporter-mediated drug interactions. Available online: https://www.fda.gov/regulatory-information/search-fda-guidance-documents/vitro-druginteraction-studies-cytochrome-p450-enzyme-and-transporter-mediated-drug-interactions (accessed on 27 September 2020).

39. Rehman, S.; Saeed, A.; Saddique, G.; Channar, P.A.; Larik, F.A.; Abbas, Q.; Hassan, M.; Raza, H.; Fattah, T.A.; Seo, S.Y. Synthesis of sulfadiazinyl acyl/aryl thiourea derivatives as calf intestinal alkaline phosphatase inhibitors. Bioorg. Med. Chem. 2018, 26, 3707-3715. [CrossRef]

Sample Availability: Samples of the compounds are not available from the authors.

(C) 2020 by the authors. Licensee MDPI, Basel, Switzerland. This article is an open access article distributed under the terms and conditions of the Creative Commons Attribution (CC BY) license (http://creativecommons.org/licenses/by/4.0/). 